\title{
Recent Advances in Oral Healthcare- A Review
}

\section{Deepak Sharma1, Shalini Chandel², Vinay Kumar Bhardwaj3 ${ }^{3}$ Arun Singh Thakur ${ }^{4}$, Pravesh Jhingta ${ }^{5}$, Nishant Negi ${ }^{6}$}

${ }^{1}$ Assistant Professor, Department of Periodontology, HP Government Dental College and Hospital, Shimla, India. 2 Intern, HP Government Dental College and Hospital, Shimla, India.

${ }^{3}$ Professor, Department of Public Health Dentistry, HP Government Dental College and Hospital, Shimla, India.

${ }^{4}$ Assistant Professor, Public Health Dentistry, HP Government Dental College and Hospital, Shimla, India.

5Professor, Department of Periodontology, HP Government Dental College and Hospital, Shimla, India. ${ }^{6}$ Assistant professor, Department of Orthodontics and Dentofacial orthopaedics, HP Government Dental College and Hospital, Shimla, India.

$\underline{\text { Review Article }}$

Address for Correspondence Author

Dr. Deepak Sharma; Department of Periodontology, HP Government Dental College and Hospital, Shimla, India.

E-mail: deepakrajdoctor@gmail.com

Crossref doi: https://doi.org/10.36437/ijdrd.2020.2.3.H

\section{ABSTRACT}

Advances in technology have transformed the dentistry to optimize patient care and satisfaction. This has made dental care more efficient, comfortable, and accessible. Dentists continue to utilise high-quality treatment approaches which are more accurate, faster, and precise than traditional methods. Leading-edge equipment and technological researches will give oral health care providers more confidence and predictability, resulting in improved healthcare for their patients.

Keywords: Technology, Internet, Robots, Regeneration, Gene.

\section{Introduction}

As technology transform every aspect of healthcare, medicine, and the pharmaceutical industry, dentistry will incorporate these breakthroughs to improve the prevention, diagnosis, treatment of dental problems. Advances in technology will provide a comfortable environment for the dentist and patient as per the individual preference and doctors' requirements. It will help the dentists in precise diagnosis and proper care of the patient. There will be the development of devices embedded with software, a sensor that will exchange data with the Internet and will be used for forecasting a health problem that may occur in the future. ${ }^{1}$ The application of gene-editing tools, robotics, regenerative, and personalised medicine will revolutionise the field of clinical dentistry. Dentists, researchers, and scientists continue adopting these technological developments to improve dental health with minimally invasive and efficient methods. The article presents a curated list of spectacular medical technology innovations, from augmented reality to artificial intelligence, tissue engineering, and regeneration. 


\section{Internet of Things (IOTs) and Artificial Intelligence (AI)}

Internet of things (IoT) is a significant application of computer engineering which has an extensive role in designing and making smart products and services in the field of dentistry. ${ }^{1}$

\section{A. Smart Toothbrush}

Let's start with one of the most interesting technologies - smart toothbrush. Everything we buy nowadays is "smart"- smartphones, smartwatches, smart houses. Smart toothbrushes have entered the technology and they are proving to have many benefits. Sensors in the head of the toothbrush send information about brushing habits to an app on the user's phone. The smart toothbrush records brushing times, how long different areas of the mouth are brushed, how much pressure is applied, and what angle the brush is held at. The smart toothbrush teaches users how to fully optimise their plaque control and oral health.

\section{B. Augmented Reality (AR) and Virtual Reality (VR)}

AR is to "virtualize" the virtual image into the real space and creating a completely virtual space around the user's eyes to replace the real space. It helps the users to see a world that has a real environment and is generated by computer graphics over a real scene. ${ }^{1}$ VR offers the users a real image inside the virtual 3D model. To build a three-dimensional image, the true virtual world forms in the user's eyes. VR is also with special glasses to cover the user's surrounding vision to achieve the desired situation. ${ }^{2}$ VR and AR not only integrate systems for learning and teaching perspective but also for training skills and improve the hand-eye coordinate, posture and skills. ${ }^{3}$

VR and AR system has become an educational tool to make the students learn by themselves and also decreases faculty time by fivefold when compared to traditional preclinical teaching methods. ${ }^{4}$ Not only applied to education, but also developed in the clinical treatment. The VR and AR training and lesson can spread and apply to every department of dentistry to make the student train their skill by themselves. And because of the complete education and training in the surgery, it would decrease the risk and create a safe surgical environment. In surgery, it includes accurate medical images, tracking systems, and targeting to help the physicians execute the surgery.

\section{Teledentistry}

The term "Teledentistry" was first used in 1997 when Cook defined it as the practice of using videoconferencing technologies to diagnose and provide advice about treatment over a distance. It is a combination of telecommunications and dentistry, involving the exchange of clinical information and images over remote distances for dental consultation and treatment planning. ${ }^{5,6}$ Teledentistry can take place in three ways.

\section{a. Real-Time consultation,}

\section{b. Store-and Forward Method,}

\section{c. Remote Monitoring method.}

Real-Time Consultation involves a videoconference in which dental professionals and their patients, at different locations, may see, hear, and communicate with one another.7 "Store-and-Forward" Method involves the exchange of clinical information and static images collected and stored by the dental practitioner, who forwards them for consultation and treatment planning. ${ }^{8}$

"Remote Monitoring" Method, in which patients are monitored at a distance and can either be hospital-based or home-based. ${ }^{9}$

In teledentistry practice, medico-legal and copyright issues also have to be considered. These problems arise primarily due to a lack of well-defined standards.

\section{Computer Aided Designing (CAD) and Three Dimensional (3D) Dentistry}

3D printing is generally used to describe a manufacturing approach that builds objects one layer at a time and then adding multiple layers to form the object. This process can also be described as additive manufacturing 
and is also referred to as rapid prototyping.10,11 The apparatus includes the computer-aided design (CAD) software that allows objects and the whole assemblies to be designed in a virtual environment. ${ }^{12}$

\section{Applications of 3D Printing in Dentistry:}

\section{a. Medical Modeling}

One of the earliest applications of 3D printing in surgery is medical modelling that can be referred to as the production of an anatomical 'study model'. ${ }^{13}$ This allows, the particularly complex, unusual, or unfamiliar anatomy, to be carefully reviewed before the surgery and planning of the surgical approach before the surgery. ${ }^{14,15}$ 3D printed technology can lead to expedited, less invasive and more predictable surgery. ${ }^{16}$

\section{b. Drilling and Cutting Guides}

The use of drills and cutting guides in implant dentistry is becoming common. Use of drill and cutting guides allows a virtual 3D plan created on-screen in software, to be transferred to the operative site and as such can be thought of as an interface between the virtual plan and the physical patient. 17,18

\section{c. Crown Copings and Partial Denture Frameworks}

In fixed and removable prosthodontics, treatment may be planned and designing of the restorations can be done by using CAD software. The scanned data and CAD design is then used to mill the crown or bridge copings, implant abutment, and bridge structures. 3D printing may be harnessed for the fabrication of metal structures either indirectly by printing in burnout resins or waxes for a lost-wax process, or directly in metals or metal alloys. ${ }^{19}$

\section{d. Digital Orthodontics}

In orthodontics, the treatment planning and fabrication of appliances can be done robotically based upon a digital workflow using intraoral or laboratory optical scanning or even CBCT to capture the data from the patient. The Invisalign ${ }^{\circledR}$ system digitally realigns the patient's teeth up to desired results and make a series of 3D printed models for the manufacture of 'aligners', which progressively reposition the teeth over a period of time. ${ }^{20,21}$

\section{e. Dental Implants}

3D printing has the ability to produce implants with complex geometries, such as a bone-like morphology, which may not be produced by milling alone. Manufacturers have used this technology to create novel dental implants with a porous and rough surface..$^{22,23}$

\section{Big Data}

'Big data' represents large amounts of data that are unmanageable using traditional software or internet-based platforms. It is explained by Douglas Laney. Laney observed that data was growing in three different dimensions namely, volume, velocity, and variety (known as the $3 \mathrm{Vs}$ ). What creates BIG DATA?

\section{A. Data Accumulation (Velocity)}

- Data accumulates expansively

- No economic trade-off between retaining vs. deleting data

\section{B. Data Quality (Veracity)}

- More data doesn't always give us more "value"

- Information from data becomes more valuable when the data is more reliable.

- Data-driven decision-making requires accurate and reliable data

\section{Data Size (Volume)}

- At its most elementary level

- BIG DATA is about bringing datasets together

- There is no critical mass of data alone needed to make it "Big." 


\section{Data Complexity(Variety)}

- Mix of varying types and sources of data to make it complex and large.

- Data linkages are important ${ }^{24}$

An electronic medical record (EMR) stores the standard medical and clinical data gathered from the patients. Electronic health records( EHRs), EMRs, personal health records (PHR), medical practice management software (MPM), and many other components collectively have the potential to improve the quality, service efficiency, and costs of healthcare along with the reduction of medical errors. The adoption of EHRs was slow at the beginning of the 21st century however it has grown substantially after $2009.25,26$

\section{Workflow of Big Data Analytics}

The ultimate goal of every component is to convert this huge data into an informative knowledge base. The application of bioinformatics approaches to transform the biomedical and genomics data into predictive and preventive health is known as translational bioinformatics, which is at the forefront of data-driven healthcare. Various kinds of quantitative data in healthcare, for example from laboratory measurements, medication data, and genomic profiles, can be combined and used for precision therapies. ${ }^{27}$ The application of big data analytics in the area of dental education spans from improving student training at dental schools to continuous professional improvement and to ongoing real-time support via EHR at the point of care. ${ }^{28}$

\section{Personalised Medicine}

This allows a new patient care environment as the greater value will be placed on disease prevention and risk assessment. The goal is to minimize the onset and progression of chronic disease. This strategy is facilitated through an analysis of a patient's genomic profile and environmental and cultural influences that impact disease risk. In turn, this data can be used to both develop personalized precision therapy and predict the patient's response to therapy. ${ }^{29,30}$ Complex dental diseases such dental caries, orofacial pain, and oral cancer, are examples where its application has the potential to mitigate by taking a more proactive approach to disease diagnosis and therapy rather than our current reactive, wait and see approach. ${ }^{31}$ If dentists want to implement the concept of personalised medicine in practice, they will need to have a deeper understanding of the relationship between oral and systemic health, working knowledge of the power and limitations of genomic medicine. They should be proficient in the use of new diagnostic tools and be an effective member of an integrated healthcare team. ${ }^{32}$ This will enable practitioners to mitigate disease progression by revealing actionable therapeutic targets. In this regard, personalized medicine will have a the transformative effect on dental practice. ${ }^{33}$

\section{Robotics}

Robotics is a branch of technology that specializes in designing, construction, operation, and application of robots as well as the computer systems for its control, sensory feedback, and processing the information. According to the Robot Institute of America, a robot is defined as "a reprogrammable, multifunctional manipulator designed to move materials, parts, tools or specialized devices through various programmed motions for the performance of a variety of tasks". The intervention of robotics in the field of dentistry can offer improved and precise treatment with good quality of work in less amount of time.

\section{a) Surgical Robots}

Oral and maxillofacial surgery has a new kind of surgical robot which is programmed beforehand in order to perform the various functions in the operation theatre and also interact with the surgeon and provides a new environment in the operating room..$^{34,35,36}$ 


\section{b) Sensor equipped implant setup}

In the preoperative stage, it uses 3D views obtained from the images of the patient before surgery followed by the intraoperative stage in which it shows the 3D orientation of position of instruments and trajectories which are displayed on the monitor within patient's 3D imaging data. ${ }^{37}$

\section{c) Robotic Dental Drill}

It works by immobilizing the patient's jaw and suspending thin needles which will penetrate the gum and determine the location of the bone. This whole unit is connected with a wireless connection to a PC and CT scan data thereby producing a set of drill guides which is self-directing and can be altered by the clinician as per requirement.

\section{d) Tooth Arrangement Robot}

It is a single manipulator system that manufactures complete dentures. The various functions of this software are to choose and create medical history files of the patient followed by drawing a jaw arch and dental arch curves and finally to adjust the dental arch curve. It also displays the 3D virtual dentitions. Using this robot system, the manufacturing of complete dentures takes only 30 minutes. ${ }^{38}$

\section{e) Dental Implantology Robot}

This technology of robot implant denture from preoperative planning to splint drilling was established by Ecole des Mines de Paris in France and Umea Universities in Sweden. This method consists of forming preprogrammed software that is used with CT scanner data. ${ }^{39,40}$ Another system using the ABB IRB2400/M98 robot is brought about by the University of Coimbra in Portugal. It performs the implant drilling and applies pressure on the gathered implants to mimic the mastication process. ${ }^{41}$

\section{f) Orthodontic Archwire Bending Robots}

This technology for automatically bending orthodontic wires was devices by Werner Butscher. The bending apparatus is known as the Suresmile archwire bending robot. ${ }^{42} \mathrm{~A}$ type of archwire bending robot is based on MOTOMAN UP6 is composed of PC and archwire bending actuator. This connects with the MOTOMAN robot end and is used to stabilize and bend the archwire.43,44 The various other things analyzed by this robot include bending position, angle of optimization of the archwire, the kinematics and bending properties. ${ }^{45-48}$

\section{Regenerative Dentistry and Tissue Engineering}

Because of their differentiation capacity and angiogenic properties, dental pulp-derived stem cells (DPSCs) have the potential to regenerate dentin and dental pulp tissue. DPSCs can be obtained from postnatal teeth, extracted wisdom teeth, or exfoliated deciduous teeth. Due to their differentiation potential, the mesenchymal stem cells are promising for tooth repair. This repair works by stimulating stem cells to encourage the growth of dentin and pulp and allowing patients to effectively regrow dental tissue that has been damaged through disease. Two strategies can be applied to dental tissue regeneration.

\section{A. Cell Transplantation \\ B. Cell Homing}

Cell transplantation includes transplanting exogenous stem cells loaded onto scaffolds, incorporated with signalling molecules, into the root canal system of the host to allow regeneration.

Cell homing is defined as active recruitment of endogenous cells, including stem/progenitor cells, into an anatomic compartment. It allows tissue repair and regeneration through chemotaxis of host endogenous cells to injured tissue via biological signalling molecules. Cell transplantation therapy has many hurdles in its way in clinical translation because complex procedures need to be followed, such as tooth extraction, pulp extirpation, in vitro cell culture, selection of stem cells or progenitor cells, ex vivo cell expansion, storage, and 
shipping. Thus, compared with stem cell transplantation, cell homing techniques might be easier to perform clinically as there is no need for manipulation and isolation of stem cells in vitro.

\section{Advances in Gene Editing Tools}

CRISPR stands for Clustered Regularly Interspaced Short Palindromic Repeats. This refers to clusters of DNA sequences that are found at regular intervals in the genome of living organisms. Cas9 is an RNA-guided DNA endonuclease enzyme that acts like a pair of molecular scissors to cut strands of DNA. Bacteria capture pieces of DNA from invading bacteriophage and use them to create DNA snippets known as CRISPR arrays. The CRISPR arrays allow the bacteria to remember the bacteriophage. If bacteriophage attacks again, the bacteria produce RNA segments from the CRISPR arrays to target their DNA. The bacteria then use Cas9 or a similar enzyme to cut the DNA apart, which disables the bacteriophage. CRISPR "spacer" sequences are transcribed into short RNA sequences (CRISPR RNA or crRNA) capable of guiding the CRISPR- CAS9 system to match sequences of DNA. When the target DNA is found, Cas9 binds to the DNA and cuts it thus shutting the targeted gene off.

\section{CRISPR'S role in Dentistry}

CRISPR-CAS9 system will be able to identify the causative genes in many oral pathologies and disorders including early childhood dental caries. CRISPR will also help in the identification of genes that suppress the tumor-promoting properties of the genes that cause oral cancer. Gene editing technology, with its ability to identify, delete, or replace genes can improve the prognosis of Squamous cell carcinoma of the oral cavity that arises due to viral and bacterial factors. ${ }^{49,50,51}$

\section{Conclusion}

Scientific discoveries, latest technological advances have brought transformations in all fields of health care including dentistry. Dental treatment is moving into a period of fewer invasive and more preventive interventions to improve quality of dental care. The paper reviewed recent advances in oral health care technology, materials, devices and clinical approaches with potential to improve the prevention, diagnosis and treatment of oral diseases.

\section{References}

1. Haleem A, Javaid M, Khan IH. Internet of things (IoT) applications in Dentistry. Current Medicine Research and Practice. 2020; 10: 80-81.

2. M.T. Schultheis, A.A. Rizzo. The application of virtual reality technology in rehabilitation. Rehabil Psychol. 2001; 46: 296- 311. https://psycnet.apa.org/doi/10.1037/0090-5550.46.3.296

3. E. Roy, M.M. Bakr, R. George. The need for virtual reality simulators in dental education: a review. Saudi Dent J. 2017; 29: 41- 47. https://dx.doi.org/10.1016\%2Fj.sdentj.2017.02.001

4. T.K. Schleyer, T.P. Thyvalikakath, H. Spallek, M.P. Dziabiak, L.A. Johnson. From information technology to informatics: the information revolution in dental education. J Dent Educ. 2012; 76: 142- 153. https://doi.org/10.1002/j.0022-0337.2012.76.1.tb05241.x

5. Yoshinaga L. The Use of Teledentistry for Remote Learning Applications. Pract Proced Aesthet Dent. 2001; 13: 327-89. https://pubmed.ncbi.nlm.nih.gov/11402774/

6. Fricton J, Chen H. using Teledentistry to Improve Access to Dental Care for the Underserved. Dent Clin North Am. 2009; 53:537-48. https://doi.org/10.1016/i.cden.2009.03.005

7. Bhambal A, Saxena S, Balsaraf SV. Teledentistry: Potentials Unexplored. J Int Oral Health. 2010; 2:1-6. https://www.ispcd.org/userfiles/rishabh/iioh-02-03-01.pdf 
8. Chang SU, Plotkin DR, Mulligan R, Polido JC, Mah JK, Meara JG. Teledentistry in Rural California-A USC Initiative. CDA J. 2003; 31: 601-8. https://pubmed.ncbi.nlm.nih.gov/13677402/

9. Weerasinghe JU. Clinical Trials on Computer Based Telemedicine-A Systematic Review. Sri Lankan J Bio-Med Inform. 2010; 1:12-20. http://doi.org/10.4038/sljbmi.v1i1.1481

10. Andonović V, Vrtanoski G . Growing rapid prototyping as a technology in dental medicine. Mech Eng Sci J 2010; 29: 31-39.

11. Liu Q, Leu M C, Schmitt S M. Rapid prototyping in dentistry: technology and application. Int J Adv Manuf Technol 2006; 29: 317-335. https://link.springer.com/article/10.1007/s00170-0052523-2

12. van Noort R . The future of dental devices is digital. Dent Mater 2012; 28: 3-12. https://doi.org/10.1016/i.dental.2011.10.014

13. Kurenov S N, Ionita C, Sammons D, Demmy T L. Three-dimensional printing to facilitate anatomic study, device development, simulation, and planning in thoracic surgery. J Thorac Cardiovasc Surg 2015; 149: 973-979. https://doi.org/10.1016/j.jtcvs.2014.12.059

14. Sinn D P, Cillo J E Jr, Miles B A . Stereolithography for craniofacial surgery. J Craniofac. Surg 2006; 17: 869-875. https://doi.org/10.1097/01.scs.0000230618.95012.1d

15. Van Assche N, van Steenberghe D, Guerrero M E et al. Accuracy of implant placement based on pre-surgical planning of three-dimensional cone-beam images: a pilot study. Clin Periodontol 2007; 34: 816-821. https://doi.org/10.1111/j.1600-051x.2007.01110.x

16. Sanna A, Molly L, van Steenberghe D. Immediately loaded CAD-CAM manufactured fixed complete dentures using flapless implant placement procedures: a cohort study of consecutive patients. J Prosthet Dent 2007; 97: 331-339. https://doi.org/10.1016/s0022-3913(07)60021-3

17. Flügge T V, Nelson K, Schmelzeisen R, Metzger M C . Three-dimensional plotting and printing of an implant drilling guide: simplifying guided implant surgery. J Oral Maxillofac Surg 2013; 71: 1340-1346. https://doi.org/10.1016/i.joms.2013.04.010

18. Chen J, Zhang Z, Chen X, Zhang C, Zhang G, Xu Z . Design and manufacture of customized dental implants by using reverse engineering and selective laser melting technology. J Prosthet Dent 2014; 112: 1088-1095. https://doi.org/10.1016/j.prosdent.2014.04.026

19. Vandenbroucke B., Kruth JP. Direct Digital Manufacturing of Complex Dental Prostheses. In: Bártolo P., Bidanda B. (eds) Bio-Materials and Prototyping Applications in Medicine. Springer, Boston, MA. 2008 https://doi.org/10.1007/978-0-387-47683-4

20. Tuncay 0 . The Invisalign System. New Malden: Quintessence Publishing Co., Ltd, 2006.

21. Neil Pender. The Invisalign ${ }^{\circledR}$ system, European Journal of Orthodontics. 2007; 29(3):322-323. https://doi.org/10.1093/ejo/cjm029

22. Chen J, Zhang Z, Chen X, Zhang C, Zhang G, Xu Z . Design and manufacture of customized dental implants by using reverse engineering and selective laser melting technology. J Prosthet Dent 2014; 112: 1088-1095. https://doi.org/10.1016/j.prosdent.2014.04.026

23. Xiong Y, Qian C, Sun J. Fabrication of porous titanium implants by three dimensional printing and sintering at different temperatures. Dent Mater J 2012; 31: 815. https://doi.org/10.4012/dmj.2012-065

24. Laney D. 3D data management: controlling data volume, velocity, and variety, Application delivery strategies. Stamford: META Group Inc; 2001. https://blogs.gartner.com/douglaney/files/2012/01/ad949-3D-Data-Management-Controlling-Data-Volume-Velocity-andVariety.pdf 
25. Reisman M. EHRs: the challenge of making electronic data usable and interoperable. Pharm Ther. 2017; 42(9):572-5. https://www.ncbi.nlm.nih.gov/pmc/articles/PMC5565131/

26. Murphy G, Hanken MA, Waters K. Electronic health records: changing the vision. Philadelphia: Saunders W B Co; 1999. p. 627.

27. Li L, et al. Identification of type 2 diabetes subgroups through topological analysis of patient $\begin{array}{llllll}\text { similarity. } & \text { Sci } & \text { Transl } & \text { Med. 2015; }\end{array}$ https://doi.org/10.1126/scitranslmed.aaa9364

28. Adam J, Bore M, Childs R, Dunn J, Mckendree J, Munro D, Powis D. Predictors of professional behaviour and academic outcomes in a UK medical school: a longitudinal cohort study. Med Teach. 2015; 37(9): 868- 80. https://doi.org/10.3109/0142159x.2015.1009023

29. Regierer B, Zazzu V, Sudbrak R, Kuhn A, Lehrach H. Future of medicine: models in predictive diagnostics and personalized medicine. Adv. Biochem. Eng. Biotechnol. 2013; 133:15-33. https://doi.org/10.1007/102012 176

30. Divaris K. Fundamentals of precision medicine. Compend. Contin. Educ. Dent. 2017; 38(8Suppl.): 30-32. https://www.ncbi.nlm.nih.gov/pmc/articles/PMC5880533/

31. Kornman KS, Duff GW. Personalized medicine: will dentistry ride the wave or watch from the beach? J. Dent. Res. 2012; 91(7 Suppl.): 8S-11S. https://doi.org/10.1177/0022034512449171

32. Hakim F, Kachalia PR. Implementation strategies for incorporating new technologies into the dental practice. J. Calif. Dent. Assoc. 2010; 38(5):337-341. https://europepmc.org/article/med/20572528

33. Snyderman R, Meade C, Drake C. Value of personalized medicine. JAMA 2016; 315(6):613-614. https://doi.org/10.1001/jama.2015.17136

34. DiGioia AM, Colgan BD, Koerbel N Computer aided surgery. In: Satava RM (Ed.), Cybersurgery: Advanced Technologies for Surgical Practice. John Wiley \& Sons, New York, USA, 1998; pp.121139.

35. Lueth TC, Hein A, Albrecht J, Demirtas M, Zachow S, et al. A Surgical Robot System for Maxillofacial Surgery. IEEE, Germany, Europe, 198; pp. 2470-2475.

36. Barone, S., Casinelli, M., Frascaria, M. et al. Interactive design of dental implant placements through CAD-CAM technologies: from 3D imaging to additive manufacturing. Int J Interact Des Manuf. 2016; 10:105-117. https://link.springer.com/article/10.1007/s12008-014-0229-0

37. Hoffmann WJ, Roman GG, Reiner. Accuracy of navigation-guided socket drilling before implant installation compared to the conventional free-hand method in a synthetic edentulous lower jaw model. Clin Oral Implants 2005; 16(5): 609-614. https://doi.org/10.1111/j.1600$\underline{0501.2005 .01153 . X}$

38. Zhang, Y., Zhao, Z., Song, R., Lu, J., Lu, P. and Wang, Y. Tooth arrangement for the manufacture of a complete denture using a robot. Industrial Robot 2001; 28(5):420-25.

39. Dutreuil J, Goulette F, Laurgeau C, Zoreda JC, Lundgren S Computer assisted dental implantology: a new method and a clinical validation. Medical Image Computing and Computer-Assisted Intervention-MICCAI 2001; 384-391. https://link.springer.com/chapter/10.1007/3-540-45468$\underline{346}$

40. Chen XJ, Wang CT, Lin YP (2005) A computer-aided oral implantology system. Proceedings of the IEEE-EMBS 27th Annual International Conference of the Engineering in Medicine and Biology Society 3312-3315. 
41. Pires JN, Caramelo FJ, Brito P, Santos J, Botelho MF Robotics in implant dentistry: stress/strain analysis. System overview and experiments. Industrial Robot. 2006; 33(5): 373-380. https://doi.org/10.1108/01439910610685043

42. Rigelsford J. Robotic bending of orthodontic archwires. Industrial Robot 2004; 31(6): 321-335. https://doi.org/10.1108/ir.2004.04931fad.007

43. Zhang Y, Jia Y The control of archwire bending robot based on MOTOMAN UP6. Proceedings of the 2nd International Conference on Biomedical Engineering and Informatics, 2009; 1-5. https://doi.org/10.1109/BMEI.2009.5305333

44. Du H, Jia Y, Zhang Y, Liu Y Trajectory planning of archwire bending robot. China Mechanical Engineering 2010; 21(13): 1605-1608.

45. Jiang JX, Zhang YD, Liu YJ. Algorithms comparison of control points planning of target archwire," ICIC Express Letters. Part B: Applications. 2012; 3(4): 923-930.

46. Jiang JX, Zhang YD. Searching control points of formed archwire based on dichotomy and multiobjective optimization method. Journal of Computational Information Systems. 2012; 8(6): 2309-2316.

47. Zhang Y, Jiang J. Optimization algorithm of control points planning of archwire bending forming," International Journal of Digital Content Technology and its Applications 2012; 6(22): 590-599.

48. Zhang Y, Jiang J. Kinematics analysis and simulation study of an archwire bending robot. Chinese High Technology Letters.2012; 22(7): 727-734.

49. Jangam DK, Talreja KM. European Journal of Biomedical and Pharmaceutical Sciences. 2020; $7(6): 314-320$.

50. Wang H, La Russa M, Qi LS. CRISPR/Cas9 in Genome Editing and Beyond. Annu Rev Biochem. 2016; 85:227-264.

51. Sinha N, Shankar D, Vaibhav V, Vyas T, Singh A, Parihar AS. Oral health-related quality of life in children and adolescents of Indian population. J Pharm Bioall Sci 2020;12, Suppl S1:619-22. https://doi.org/10.4103/jpbs.JPBS 11320

How to cite this Article: Deepak Sharma ${ }^{1}$, Shalini Chandel2, Vinay Kumar Bhardwaj ${ }^{3}$, Arun Singh Thakur4, Pravesh Jhingta5, Nishant Negi6: Recent Advances in Oral Healthcare- A Review Int. J. Drug Res. Dental Sci., 2020; 2(3): 55-63.

Crossref doi: https://doi.org/10.36437/ijdrd.2020.2.3.H

Source of Support: Nil, Conflict of Interest: Nil.

Received: 21-7-2020 Revised: 25-8-2020 Accepted: 28-8-2020 